\title{
Short Communication Effect of $\kappa$-opioid receptor agonist on the growth of non-small cell lung cancer (NSCLC) cells
}

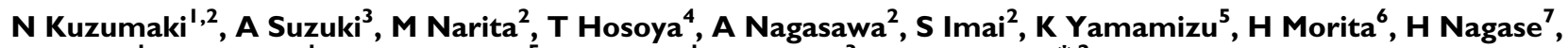 \\ Y Okada', HJ Okano', JK Yamashita ${ }^{5}$, H Okano', T Suzuki ${ }^{3}$ and M Narita*,2 \\ 'Department of Physiology, Keio University, School of Medicine, 35 Shinanomachi Shinjuku-ku, Tokyo 160-8582, Japan; ²Department of Pharmacology, \\ Hoshi University School of Pharmacy and Pharmaceutical Sciences, 2-4-4I Ebara, Shinagawa-ku, Tokyo I42-850 I, Japan; 'Department of Toxicology, \\ Hoshi University School of Pharmacy and Pharmaceutical Sciences, 2-4-4I Ebara, Shinagawa-ku, Tokyo 142-850 I, Japan; ${ }^{4}$ Biological Systems Control \\ Team Biomedicinal Information Research Center, Aomi 2-4-7, Koto-ku, Tokyo 135-0064, Japan; ${ }^{5}$ Laboratory of Stem Cell Differentiation, Stem Cell \\ Research Center, Institute for Frontier Medical Sciences, Kyoto University, 53 Shogoin Kawahara-cho, Sakyo-ku, Kyoto 606-8507, Japan; ${ }^{6}$ Faculty of \\ Pharmaceutical Sciences, Hoshi University School of Pharmacy and Pharmaceutical Sciences, 2-4-4I Ebara, Shinagawa-ku, Tokyo I42-850 I, Japan; \\ ${ }^{7}$ Laboratory of Medical Chemistry, School of Pharmacy, Kitasato University, Tokyo, Japan
}

BACKGROUND: It is becoming increasingly recognised that opioids are responsible for tumour growth. However, the effects of opioids on tumour growth have been controversial.

METHODS: The effects of $\kappa$-opioid receptor (KOR) agonist on the growth of non-small cell lung cancer (NSCLC) cells were assessed by a cell proliferation assay. Western blotting was performed to ascertain the mechanism by which treatment with KOR agonist suppresses tumour growth.

RESULTS: Addition of the selective KOR agonist U50,488H to gefitinib-sensitive (HCC827) and gefitinib-resistant (HI975) NSCLC cells produced a concentration-dependent decrease in their growth. These effects were abolished by co-treatment with the selective KOR antagonist nor-BNI. Furthermore, the growth-inhibitory effect of gefitinib in HCC827 cells was further enhanced by cotreatment with $\mathrm{U} 50,488 \mathrm{H}$. With regard to the inhibition of tumour growth, the addition of $\mathrm{U} 50,488 \mathrm{H}$ to $\mathrm{HI} 975$ cells produced a concentration-dependent decrease in phosphorylated-glycogen synthase kinase $3 \beta$ (p-GSK3 $\beta$ ).

CONCLUSION: The present results showed that stimulation of KOR reduces the growth of gefitinib-resistant NSCLC cells through the activation of GSK3 $\beta$.

British Journal of Cancer (2012) 106, I| 48- I 152. doi: I0.1038/bjc.201 I.574 www.bjcancer.com

Published online 16 February 2012

(c) 2012 Cancer Research UK

Keywords: $\kappa$-opioid receptor; non-small cell lung cancer; gefitinib

Opioids are small endogenously produced peptide molecules that are widely known for their analgesic and psychoactive properties (Ciccone et al, 1980; Zubieta et al, 2001; Moles et $a l, 2004)$. It has been shown that opioids can promote the growth of tumour cells (Lazarczyk et al, 2010). On the other hand, it has been controversially reported that opioids induce the apoptosis of immunocytes, cancer cells and neuroblastoma cells (Boehncke et al, 2010). Thus, it is becoming increasingly recognised that opioids have a role in tumour growth (Saurer et al, 2008).

Three major types of opioid receptors, $\mu, \delta$ and $\kappa$, have been well characterised. $\kappa$-Opioid receptors (KORs) are widely expressed throughout the central nervous system (Chavkin et al, 1982; Dhawan et al, 1996). It has been reported that KOR is also expressed in the human adenocarcinoma breast cancer cell line MCF7 and small cell lung carcinoma (Kallergi et al, 2003). Furthermore, KOR agonist has been shown to inhibit the growth of H157 cell, which is a non-small cell lung cancer (NSCLC) cell

*Correspondence: Dr M Narita; E-mail: narita@hoshi.ac.jp

Received 23 September 201 I; revised 29 November 201 I; accepted I December 201 I; published online 16 February 2012
(Maneckjee and Minna, 1990). However, little is known about the mechanism that underlies the inhibitory effect of KOR stimulation on the growth of NSCLC cells.

Epidermal growth factor receptor (EGFR) is a major target of molecular anti-NSCLC therapy (Wakeling et al, 2002). Non-small cell lung cancer patients with L858R or exon 19 deletion mutations in EGFR show good responses to the tyrosine kinase inhibitor gefitinib. However, patients with wild-type EGFR and acquired mutation in EGFR T790M are eventually resistant to treatment with gefitinib. In this study, we examined whether the selective KOR agonist U50,488H could inhibit the growth of gefitinibsensitive and EGFR mutant (delE746-A750, L858R) NSCLC cells (HCC827) and gefitinib-resistant and EGFR mutant (T790M) NSCLC cells (H1975), and investigated the signalling mechanism of the KOR-mediated inhibitory effect on tumour cell growth.

\section{MATERIALS AND METHODS}

\section{Cell culture}

The human NSCLC cell lines HCC827 and NCI-H1975 (H1975; both from American Type Culture Collection Co., MD, USA) were 
cultured in HEPES-modified RPMI 1640 medium (Sigma-Aldrich Co., St Louis, MO, USA) with $10 \%$ fetal bovine serum (FBS; Invitrogen Life Technologies Co., Carlsbad, CA, USA) and 1\% penicillin-streptomycin (Invitrogen Life Technologies Co.). Normal human lung fibroblasts (NHLF; Lonza Inc., Allendale, NJ, USA) were cultured in fibroblast basal medium with insulin, rhFGF-B, GA-1000 and FBS (all from Takara Bio Inc., Tokyo, Japan). All cells were maintained under a humidified atmosphere of $5 \% \mathrm{CO}_{2}$ at $37^{\circ} \mathrm{C}$.

\section{Reagents}

The reagents used in the present study were gefitinib (Toronto Research Chemicals Inc., Canada), ( \pm ) trans 3,4-dichloro- $N$-methyl$\mathrm{N}$-(2-(1-pyrrolidinyl) cyclohexyl)-benzeneacetamide (U50,488H) methanesulfonate (Sigma Chemical Co.), nor-binaltorphimine dihydrochloride (nor-BNI; Tocris Cookson Ltd., St Louis, MO, USA), and 6-bromoindirubin- $3^{\prime}$-oxime (BIO; WAKO Pure Chemical Industries Ltd., Osaka, Japan).

\section{Cell viability assay}

Cell viability was determined by a cell proliferation assay using 3-(4,5-dimethylthiazol-2-yl)-2,5-diphenyltetrazolium bromide, yellow tetrazole (MTT). A $20-\mu \mathrm{l}$ of MTT solution $\left(5 \mathrm{mg} \mathrm{ml}^{-1}\right)$ was added to each well of the culture medium. After incubation for an additional $2 \mathrm{~h}$, the medium was removed and $100 \mu \mathrm{l}$ of DMSO was added to resolve the formazan crystals. Optical density was measured using a microplate reader with an absorption wavelength of $600 \mathrm{~nm}$. In each experiment, three replicates were prepared for each sample. The proportion of living cells was determined based on the difference in absorbance between the samples and controls.

\section{Immunohistochemistry}

The procedure for immunohistochemistry is described in the Supplementary Methods.

\section{RNA preparation and semiquantitative analysis by reverse transcription (RT)-PCR}

The RNA preparation and RT-PCR method are described in the Supplementary Methods.

\section{Western blotting}

Sample preparation and loading for western blotting are described in the Supplementary Methods. For immunoblot detection, membranes were blocked in Tris-buffered saline (TBS) containing $1 \%$ non-fat milk (Bio-Rad Laboratories, Hercules, CA, USA) containing $0.1 \%$ Tween 20 (Sigma-Aldrich Co.) for $1 \mathrm{~h}$ at room temperature with agitation. The membrane was incubated with primary antibody diluted in TBS $(1: 1000$ phosphorylated-EGFR (Cell Signaling Technology Inc., Boston, MA, USA), 1:500 p-Akt (Cell Signaling Technology Inc.), 1:1000 p-GSK3 $\beta$ (Cell Signaling Technology Inc.), $1: 2000$ p-STAT3 (Cell Signaling Technology Inc.), 1:750 GSK3 $\beta$ (Santa Cruz Biotechnology Inc., Santa Cruz, CA, USA), $1: 5000$ Akt (Cell Signaling Technology Inc.) and $1: 3500$ Stat3 (Cell Signaling Technology Inc.) containing $1 \%$ non-fat dried milk with $0.1 \%$ Tween 20 overnight at $4^{\circ} \mathrm{C}$. The membrane was washed in TBS containing $0.05 \%$ Tween 20 , and then incubated for $2 \mathrm{~h}$ at room temperature with horseradish peroxidase-conjugated goat antirabbit IgG (Southern Biotechnology Associates Inc., Birmingham, AL, USA) diluted 1:10000 in TBS containing 1\% non-fat dried milk containing $0.1 \%$ Tween 20 . The antigen-antibody peroxidase complex was finally detected by enhanced chemiluminescence (Pierce, Rockford, IL, USA) and visualised by exposure to Amersham Hyperfilm (Amersham Life Sciences, Arlington Heights, IL, USA).

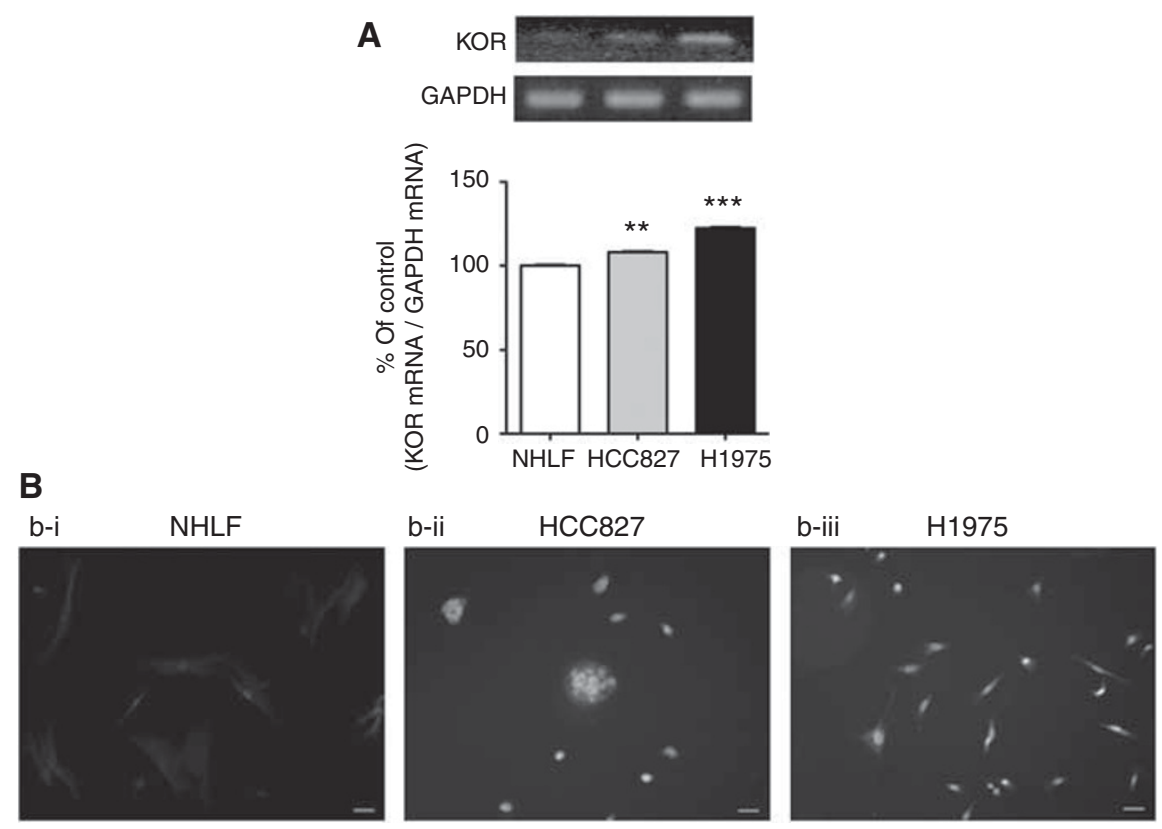

Figure I Expression of $\kappa$-opioid receptors in either NHLF, HCC827 or HI975 cells. (A) Upper: Representative RT-PCR for mRNAs of $\kappa$-opioid receptors and GAPDH, an internal standard, in each cell type. Lower: The intensity of the bands was determined semiquantitatively using Image (National Institute of Health, Bethesda, MD, USA). The values for $\kappa$-opioid receptor mRNA were normalised by the value for GAPDH mRNA. Data represent the mean with s.e.m. of five independent samples (**P $<0.01$, ***P $<0.001$ vs NHLF). (B) Distribution of the $\kappa$-opioid receptor-like immunoreactivity in either NHLF (B-i), HCC827 (B-ii) or HI975 (B-iii) cells. Scale bars $=50 \mu \mathrm{m}$ for all panels. 


\section{RESULTS}

\section{Localisation of KORs in NSCLC cells}

KORs were found in gefitinib-sensitive HCC827 cells, gefitinibresistant H1975 cells and NHLF cells, as detected by RT-PCR (Figure 1A) and immunoreactivity towards KOR antibody (Figure 1B). The expression of KOR mRNA was significantly increased in HCC827 cells $(P<0.01$ vs NHLF) and H1975 cells $(P<0.001$ vs NHLF) compared with NHLF (Figure 1).

\section{Effect of KOR agonist on the growth of the EGFR exon 19 mutant NSCLC cell line HCC827}

Addition of the KOR agonist $\mathrm{U} 50,488 \mathrm{H}$ to $\mathrm{HCC} 827$ cells for 2 days produced a concentration-dependent decrease in tumour cell growth (Figure 2A, $P<0.001$ vs non-treated group). This effect was abolished by co-treatment with the selective KOR antagonist nor-BNI (Figure $2 \mathrm{~B},{ }^{* *} P<0.001$ vs non-treated group, ${ }^{\# \#} P<0.001$ vs U50,488H-treated group). In contrast, treatment of NHLF cells with U50,488H did not affect their growth (Figure 2C). In experiments that compared the inhibition of cell growth in cells treated with gefitinib and cells treated with a combination of gefitinib and $\mathrm{U} 50,488 \mathrm{H}$, the growth-inhibitory effects in HCC827 cells were further enhanced in a dose-dependent manner (Figure 2D, $P<0.001$ vs gefitinibtreated cells).

\section{Changes in the growth of gefitinib-resistant H1975 cells by treatment with KOR agonist}

Treatment of gefitinib-resistant $\mathrm{H} 1975$ cells with U50,488H for 2 days produced a concentration-dependent and dramatic decrease in tumour cell growth (Figure $3 \mathrm{~A}, P<0.001 v s$ non-treated group). This effect was blocked by co-treatment with nor-BNI (Figure $3 \mathrm{~B}$, ${ }^{* * *} P<0.001$ vs non-treated group, ${ }^{\# \# \#} P<0.001$ vs U50,488Htreated group).

Effect of KOR agonist on the levels of phosphorylated Akt, GSK3 $\beta$ and Stat 3 in H1975 cells

There were no changes in the levels of either p-Akt or p-Stat3 in $\mathrm{H} 1975$ cells by treatment with $\mathrm{U} 50,488 \mathrm{H}$ for 2 days (Figures 3C and E). However, the addition of U50,488H to H1975 cells produced a significant and concentrationdependent decrease in $\mathrm{p}-\mathrm{GSK} 3 \beta$ (Figure $3 \mathrm{D}, P<0.001$ vs nontreated group). Furthermore, treatment with a specific GSK-3 $\beta$ inhibitor BIO produced a concentration-dependent and significant decrease in tumour cell growth (Figure $3 \mathrm{~F}, P<0.001 v s$ non-treated group).

\section{DISCUSSION}

In the present study, we investigated the role of KOR in NSCLC cells using gefitinib-sensitive HCC827 and gefitinib-resistant H1975 cells. We found that KORs were highly expressed in both cell lines. Under these conditions, addition of the selective KOR agonist U50,488H to either HCC827 or H1975 cells produced a concentration-dependent decrease in tumour cell growth. Although some of the doses of $\mathrm{U} 50,488 \mathrm{H}$ were relatively high, these effects were abolished by co-treatment with the selective KOR antagonist nor-BNI. These results support the idea that $\mathrm{U} 50,488 \mathrm{H}$ can pharmacologically act on KORs to decrease tumour growth. Additionally, the inhibition of tumour growth by gefitinib in HCC827 cells was further enhanced by co-treatment
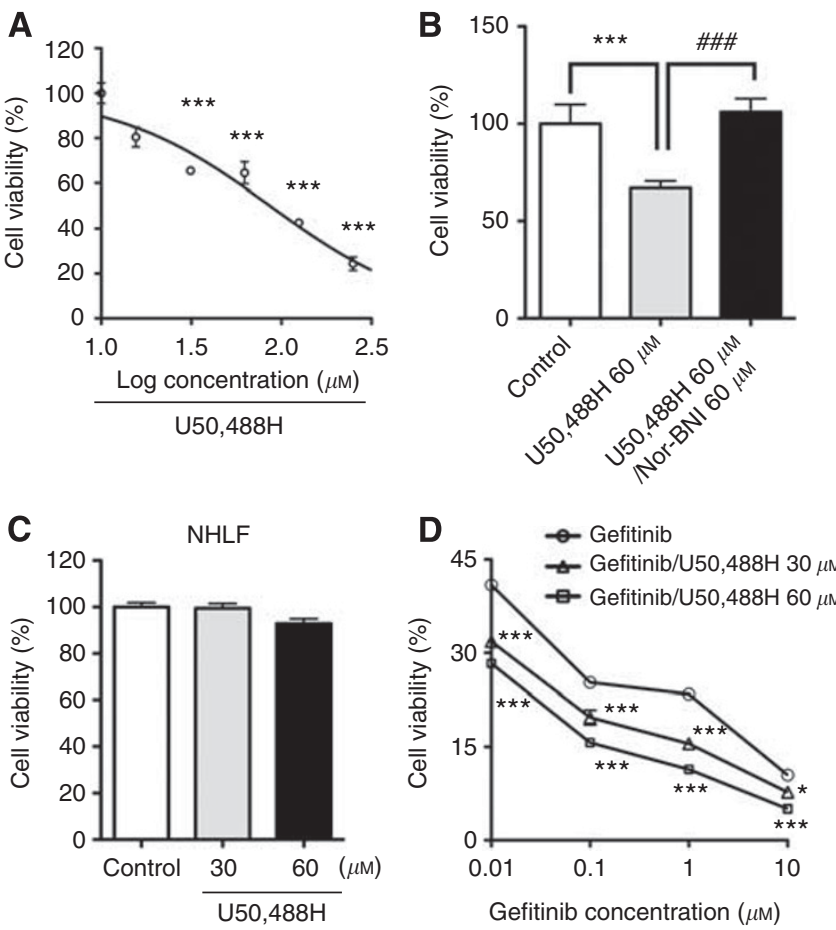

Figure 2 Effect of a $\kappa$-opioid receptor agonist on the growth of HCC827 cells. (A) Suppression of H1975 cell growth by addition of the $\kappa$-opioid receptor agonist $\mathrm{U} 50,488 \mathrm{H}(15.6-250 \mu \mathrm{M})$ for 2 days. Data represent the mean with s.e.m. of ten independent samples (*** $P<0.001$ vs non-treated group). (B) The suppression of tumour cells by $U 50,488 \mathrm{H}$ was abolished by co-treatment with $60 \mu \mathrm{M}$ of the $\kappa$-opioid receptor antagonist nor-BNI. Data represent the mean with s.e.m. of five independent samples (**** $P<0.001$ vs non-treated group, ${ }^{\# \# \# ~} P<0.00$ I vs U50,488H-treated group). (C) Treatment with $U 50,488 \mathrm{H}$ for 2 days had no effect on the growth of NHLF cells. Data represent the mean with s.e.m. of five independent samples. (D) Effect of co-treatment with U50,488H and gefitinib on the viability HCC827 cell. The data represent the mean with s.e.m. of five independent samples $\left(F_{(3,12)}=12.67, P<0.001\right.$, gefitinibtreated cells vs gefitinib plus $U 50,488 \mathrm{H}(30 \mu \mathrm{M})$-treated cells; $F_{(3,15)}=29.43$, $P<0.00$ I, gefitinib-treated cells vs gefitinib plus $U 50,488 \mathrm{H}(60 \mu \mathrm{M})$-treated cells; $* P<0.05$, $* * * P<0.001$ vs non-treated group).

with U50,488H. These findings suggest that the stimulation of KOR may provide unique opportunities for the prevention and treatment of NSCLC.

GSK $3 \beta$ is a multifunctional serine/threonine kinase that phosphorylates and thereby regulates the functions of many metabolic, signaling, and structural proteins and transcriptional factors (Grimes and Jope, 2001). EGF can inactivate GSK3 $\beta$, leading to the degradation of $\mathrm{c}-\mathrm{Myc}$ and $\beta$-catenin, which are overexpressed in tumour cells. Furthermore, the tumour suppressor $\mathrm{p} 53$ can be inactivated because of inactive GSK3 $\beta$. It has been reported that the progressive inactivation of GSK3 $\beta$, which is related to the increase in phosphorylation of GSK3 3 , is critical for the progression of lung cancer (Tian et al, 2006). In this study, treatment of $\mathrm{H} 1975$ cells with $\mathrm{U} 50,488 \mathrm{H}$ produced a significant decrease in the phosphorylation of GSK3 $\beta$. It has been recognised that activated protein kinase A (PKA) leads to phosphorylation of GSK3 $\beta$ (Fang et al, 2000), whereas activated JNK increases GSK3 $\beta$ activity ( $\mathrm{Hu}$ et al, 2009). It should be noted that the stimulation of KOR suppresses cAMP production through $\mathrm{Gi}$ proteins, which leads to the inactivation of PKA (Tso and Wong, 2003). Furthermore, the stimulation of KOR invokes the JNK cascade (Kam et al, 2004). Although the exact mechanism of 

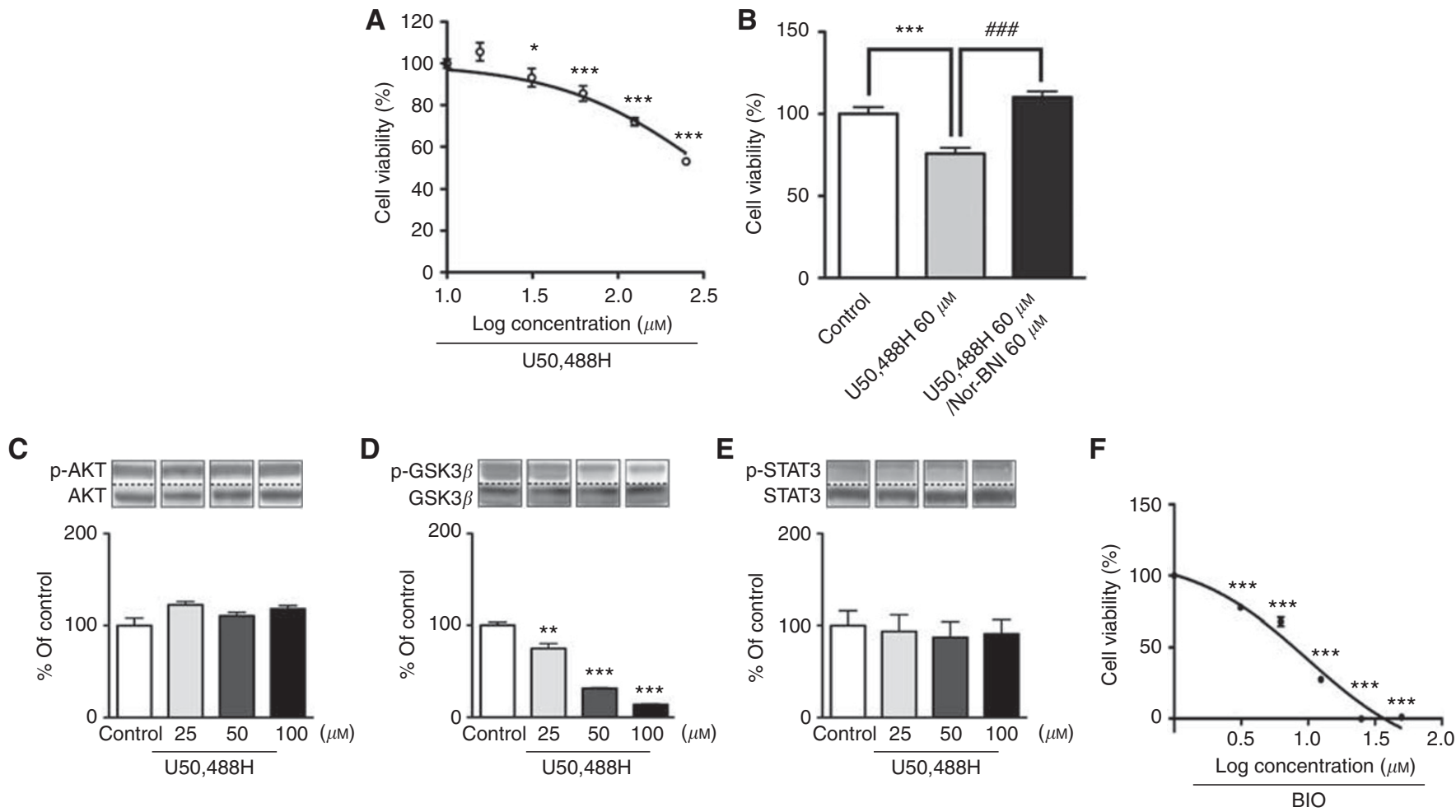

Figure 3 Effect of a $\kappa$-opioid receptor agonist on the growth of HI975 cells. (A) Suppression of HI975 cell growth by the addition of U50,488H $($ I $5.6-250 \mu \mathrm{M})$ for 2 days. Data represent the mean with s.e.m. of ten independent samples $(* P<0.05$, $* * * P<0.00$ I vs non-treated group). (B) $\cup 50,488 \mathrm{H}$ induced suppression of tumour cell growth was abolished by co-treatment with $60 \mu \mathrm{M}$ of the $\kappa$-opioid receptor antagonist nor-BNI. Data represent the mean with s.e.m. of ten independent samples (*** $P<0.00$ I vs non-treated group, ${ }^{\# \# ~} \mathrm{P}<0.00 \mathrm{I}$ vs $\cup 50,488 \mathrm{H}$-treated group). Changes in protein levels of p-AKT, p-GSK3 $\beta$ and p-STAT3 by treatment of HI975 cells with U50,488H. (C-E) Cells were treated with U50,488H $(25-100 \mu \mathrm{M})$ for 2 days. Upper: Representative western blots of p-AKT, p-GSK3 $\beta$ and p-STAT3 Lower: Representative western blots of AKT, GSK3 $\beta$ and STAT3 in membranous and cytosolic fractions of HI975 cells treated with U50,488H. Each column represents the mean with s.e.m. of five independent samples (** $P<0.01$, **** $P<0.00$ I vs non-treated group). (F) Suppression of the growth of HI 975 cells by addition of the selective GSK3 $\beta$ inhibitor BIO (3-50 $\mu \mathrm{M})$ for 2 days. Data represent the mean with s.e.m. of ten independent samples (**** $<0.001$ vs non-treated group).

KOR-mediated GSK3 $\beta$ activation remains unclear at this time, we propose that the stimulation of KOR may activate GSK3 $\beta$ through inhibition of the cAMP/PKA pathway and/or activation of the JNK pathway in NSCLC, resulting in the prevention of cancer.

In conclusion, the present results suggest that stimulation of KOR reduces the growth of NSCLC cells through the activation of

\section{REFERENCES}

Boehncke S, Hardt K, Schadendorf D, Henschler R, Boehncke WH, Duthey B (2010) Endogenous mu-opioid peptides modulate immune response towards malignant melanoma. Exp Dermatol 20: 24-28

Chavkin C, James IF, Goldstein A (1982) Dynorphin is a specific endogenous ligand of the kappa opioid receptor. Science 215: 413-415

Ciccone PE, O'Brien CP, Khatami M (1980) Psychotropic agents in opiate addiction: a brief review. Int $J$ Addict 15: 499-513

Dhawan BN, Cesselin F, Raghubir R, Reisine T, Bradley PB, Portoghese PS, Hamon M (1996) International union of pharmacology. XII. Classification of opioid receptors. Pharmacol Rev 48: $567-592$

Fang X, Yu SX, Lu Y, Bast Jr RC, Woodgett JR, Mills GB (2000) Phosphorylation and inactivation of glycogen synthase kinase 3 by protein kinase A. Proc Natl Acad Sci USA 97: 11960-11965

Grimes CA, Jope RS (2001) The multifaceted roles of glycogen synthase kinase 3beta in cellular signaling. Prog Neurobiol 65: $391-426$

Hu D, Bi X, Fang W, Han A, Yang W (2009) GSK3beta is involved in JNK2mediated beta-catenin inhibition. PLoS One 4: e6640

Kallergi G, Tsapara A, Kampa M, Papakonstanti EA, Krasagakis K, Castanas E, Stournaras C (2003) Distinct signaling pathways regulate differential
GSK3 $\beta$. Furthermore, KOR agonist might be a valuable candidate for preventing gefitinib-resistant NSCLC.

Supplementary Information accompanies the paper on British Journal of Cancer website (http://www.nature.com/bjc) opioid effects on actin cytoskeleton in malignant MCF7 and nonmalignant MCF12A human breast epithelial cells. Exp Cell Res 288: $94-109$

Kam AY, Chan AS, Wong YH (2004) Kappa-opioid receptor signals through Src and focal adhesion kinase to stimulate c-Jun N-terminal kinases in transfected COS-7 cells and human monocytic THP-1 cells. J Pharmacol Exp Ther 310: $301-310$

Lazarczyk M, Matyja E, Lipkowski AW (2010) A comparative study of morphine stimulation and biphalin inhibition of human glioblastoma T98G cell proliferation in vitro. Peptides 31: 1606-1612

Maneckjee R, Minna JD (1990) Opioid and nicotine receptors affect growth regulation of human lung cancer cell lines. Proc Natl Acad USA 87: $3294-3298$

Moles A, Kieffer BL, D'Amato FR (2004) Deficit in attachment behavior in mice lacking the mu-opioid receptor gene. Science 304: 1983-1986

Saurer TB, Ijames SG, Carrigan KA, Lysle DT (2008) Neuroimmune mechanisms of opioid-mediated conditioned immunomodulation. Brain Behav Immun 22: 89-97

Tian D, Zhu M, Chen WS, Li JS, Wu RL, Wang X (2006) Role of glycogen synthase kinase 3 in squamous differentiation induced by cigarette 
smoke in porcine tracheobronchial epithelial cells. Food Chem Toxicol 44: $1590-1596$

Tso PH, Wong YH (2003) Molecular basis of opioid dependence: role of signal regulation by G-proteins. Clin Exp Pharmacol Physiol 30: 307-316 Wakeling AE, Guy SP, Woodburn JR, Ashton SE, Curry BJ, Barker AJ, Gibson KH (2002) ZD1839 (Iressa): an orally active inhibitor of epidermal growth factor signaling with potential for cancer therapy. Cancer Res 62: 5749-5754

Zubieta JK, Smith YR, Bueller JA, Xu Y, Kilbourn MR, Jewett DM, Meyer CR, Koeppe RA, Stohler CS (2001) Regional mu opioid receptor regulation of sensory and affective dimensions of pain. Science 293: $311-315$ 